\title{
Painted Fabrics from India and Iran*
}

$\mathrm{A}^{\mathrm{I}}$

THOUGH the Indus civilisation has been known and its relation with the west recog. nised for more than ten years, its comparative study has scarcely begun. An attempt is here made to define more precisely the problems raised by its western relations.

A common tradition in the potter's craft between Mesopotamia and Sindh-Punjab can be traced back to the fourth millennium B.c. in the Uruk period. By the middle of the third millennium, this had been given a very specialised and individual expression in the Indus valley, the peculiarity of which is a free use of repetition motives, which has no parallel elsewhere in the third millennium, except perhaps in the Middle Minoan of Crete. In a random sample of sherds from Mohenjo-daro, 35 per cent of the designs were based on vegetation motives and the remaining 65 per cent were repetition motives. Indus pottery is accordingly the specialised product of a sophisticated civilisation. Moreover, it displays an astonishing uniformity over a vast territory, extending from Amri in southern Sindh to Harappa on the Ravi, five hundred miles north, which corresponds with the economic and geographical unity of the area watered by the Indus.

Sir Aurel Stein has collected a great deal of pottery from the hill country west of the Indus; but the native pottery of the hills is stylistically barbarous and shows a bewildering variety of local styles. This is due to the character of the country, broken by gorges and steep ranges. But nevertheless the wares of Baluchistan and Waziristan seem closely allied to one another and to the Indus wares, both technically and in motive. On the other hand, there are more prominent western elements than are discernible in the Indus ware, such as the sigma pattern, common in southern Baluchistan, and the 'goat motive'. These features may be due to archaism - elements which had not survived in the busy

- Substance of a paper read by Prof. V. Gordon Childe on September 12 to Section $H$ (Anthropology) at the Leicester meeting of the British Association. cities where a more sophisticated style had been elaborated.

Nevertheless in the funerary pottery from Shahitump connexions with the west that are more than mere survivals can be discerned; but these connexions are with Susa I and Samarra, not with the later cultures that flourished in Mesopotamia in the second half of the fourth and the beginning of the third millennia. The connexion with Susa $I$ is to be seen both in forms and in specialised motives, such as the 'Maltese' square decorating the centres of dishes at both sites and also at Samarra. Sherds illustrate the transition from the prevailing grey to pink, and in Sistan the same transition is illustrated, as well as that to the green tint common at al 'Ubaid. The Shahi graves reveal an extension eastward in a very pure form of Frankfort's 'Highland Culture' and precisely that form of it represented at Susa. This is no mere survival at Shahi-tump, and as all the burials are at least a thousand years later than those at Susa I and Samarra, the direction of the migration is unambiguously defined : it must have come eastward. But this affords no clue to the sources of the common elements in the Indus and Sumerian ceramic traditions.

Light will be shed on this problem when Mr. Majumdar's excavations at Amri in southern Sindh have been published. The results promise to clarify the connexion between the ceramic technique of the Indus valley and that of Mesopotamia in the fourth millennium; and they also offer a solution of some of the obscurity surrounding the Baluchi wares. It will appear that the pale-slip group is not contrasted with that of lowland India, but that the same tradition lies behind the elassical Indus ware. The Amri evidence will also explain the character of the pottery from Nal and Nundara in Baluchistan, which is more sophisticated and shows a deliberate style. This might be regarded as a development of the black-onred-on-pale-slip ware from Amri which is older than the classical Indus ware, and in turn has technical and stylistic affinities to the Jemdet Nasr ware of Mesopotamia.

\section{Atomic Weights of Potassium and Carbon}

$\mathrm{H}^{\circ}$ ÖNIGSCHMID and Goubeau in 1928 described experiments on the analysis of potassium chloride and bromide leading to an atomic weight of potassium of $39 \cdot 104$, which agrees with a value found by Richards and Archibaid in 1903, but is nearly 0.01 unit higher than the value, 39.096, obtained in 1907 by Richards and Staehler and by Richards and Mueller. Since the discrepancy is much greater than the apparent experimental error of the comparatively simple analytical operations involved, a redetermination was desirable. Zintl and Goubeau in 1927 confirmed the higher value by the conversion of potassium nitrate into the chloride. The ratio determined from the weights in air corrected to vacuum, however, and that determined from the weights of material actually weighed in vacuum, fall on opposite sides of the value to be expected from the results of Richards, Staehler and Mueller $(\mathrm{N}=14 \cdot 008)$.

Baxter and MacNevin (J. Amer. Chem. Soc.,
August), in a long series of analyses of potassium chloride, by comparison with silver, using potassium salts of different origin, find a value in satisfactory agreement with that of Richards, Staehler and Mueller, and they conclude that the atomic weight of potassium is very close to $39 \cdot 096$. No indication of a higher atomic weight was found, and the authors also report that unpublished experiments by Titus show no appreciable adsorption of air by potassium chloride and nitrate. The values found with one specimen of potassium chloride $(39 \cdot 084-39 \cdot 098)$ were low and irregular, a result not explained. No evidence of variation in the isotopic composition of potassium assimilated by plants was found by the examination of material from wood ash.

In a second paper in the same journal, Baxter and Alter report that the atomic weight of 'heavy' potassium prepared by von Hevesy by 'ideal' distillation in 1928 is $39 \cdot 109$, which is in exact agreement with the value for this material found by 